\title{
Service Radius Model and Service Scope Optimization of City Public Parking Garage
}

\author{
Chao Zeng, Boming Tang, and Tangzhi Liu \\ School of Civil Engineering \& Architecture, Chongqing Jiaotong University, Chongqing 400074, China \\ Correspondence should be addressed to Chao Zeng; 174408293@qq.com
}

Received 9 December 2015; Revised 16 April 2016; Accepted 23 May 2016

Academic Editor: Matteo Gaeta

Copyright (C) 2016 Chao Zeng et al. This is an open access article distributed under the Creative Commons Attribution License, which permits unrestricted use, distribution, and reproduction in any medium, provided the original work is properly cited.

\begin{abstract}
The service radius of public parking garage is related to the supply of parking spots and parking behavior characteristics of drivers. However, the empirical and statistical methods in the optimization of public parking garage have limitations. Based on the theory of value engineering and satisfaction, an optimization model for public parking garage service radius is established, which satisfies the requirements of both drivers and owners. Then, an amended model is proposed by using accessibility theory and the principle of moment balance. This model, in consideration of city resistance and walking impedance, is modified from the circular service scope to an irregular polygon, which is more suitable for the actual situation. Finally, the method is verified by a practical example. The results suggest that the optimization model of the service radius and the optimization method of service scope can not only balance the needs of drivers and public parking garages' owners, but also improve the operation efficiency of parking garages, so that they are more fit for the actual situation of parking service areas. This paper provides new ideas and methods to determine public parking garage service radius and service scope.
\end{abstract}

\section{Introduction}

The best layout for public parking garages should be "dispersed, nearby, and convenient," as the main function is to undertake the overflow of vehicles when the parking spots are saturated within the service radius. However, central district resources are scarce, so public parking garages are usually situated in the corner of the central areas with a service radius from $200 \mathrm{~m}$ to $500 \mathrm{~m}$ or $1000 \mathrm{~m}$, chosen according to Chinese current codes or local standards. A concentric circle service scope simply taken with the service radius fails to consider city characteristics and differences between parking behaviors. Thus, most of them have an unreasonable service radius and limitations on corner locations, which lead to low utilization of public parking garages and a waste of resources or difficulty in alleviating parking congestion.

Current transportation researches still lack practical tools and methodologies to analyze the service radius and service scope of public parking garages. The latest research mainly focuses on the public parking site selection, drivers' parking choice behaviors, and the impact of curbside parking regulation on public parking garage demand. In the field of public parking site selection, a group web-based MC-SDSS (the integration of GIS and Multicriteria Decision Analysis capabilities into the web platform offers an effective Multicriteria Spatial Decision Support System) devoted to solving parking site selection problems is presented ("as discussed by Jelokhani-Niaraki and Malczewski [1]"). Based on GIS, a novel algorithm and model for estimating city parking patterns are presented ("as discussed by Levy and Benenson [2]"). In the field of drivers' parking choice behaviors, radial distance to parking, and availability of P\&R sites in the direction of travel, gender, age, and income are found to be important factors in parking usage of city center ("as discussed by Clayton et al. [3]"). Upon arrival, parking search is shown to be dominant amongst drivers' strategies. Uncertain parking availability has been found to be important for parking location choice ("as discussed by Chaniotakis and Pel [4]"). A multinomial regression analysis shows that personal (gender, education, and country of residence) and trip (visit frequency) characteristics are significantly related to the distinguished habitual parking behavior levels ("as discussed by van der Waerden et al. [5]"). The research finds 
that, firstly, vehicle age is a key variable when choosing parking places in Spain; second, the perception of the parking charge is fairly heterogeneous, depending on both the drivers' income levels and whether or not they are local residents ("as discussed by Ibeas et al. [6]"). The results show that parking prices affect car usage; meanwhile, time limitation and the amount of parking demands affect the choice on the type of parking ("as discussed by Simićević et al. [7]"). In the field of the impact of curbside parking regulation on public parking garage demand, the research shows that the characteristics of curbside parking spaces (allowance and time limits) play a role in garage demand determination, yet pricing is a much more efficient trigger for behavioral change ("as discussed by Gragera and Albalate [8]"). Through establishing competition models between private parking garages and public curbside parking, the research found that drivers differ in their parking durations, searching-time costs, and walking-time costs ("as discussed by Inci and Lindsey [9]"). The optimal model for public management can explain how cities maximize the public benefits of their parking assets and provide a reasonable price for off-street parking ("as discussed by Pierce et al. [10]").

Researches focused on the service radius and service scope of public parking garage are far less well developed. And related studies mainly concentrate on two aspects: the statistical analysis of the walking distance after parking ("as discussed elsewhere [11, 12]") and establishing an optimization service radius model according to parking choice probability models ("as discussed by Yu Yang et al. [13]"). The methods for determining service radius of public parking garage are mostly simple statistical analysis of the walking distance after parking ("as discussed by USA City Land Use Institute [14]") or adopting the minimum average of the walking distance after parking as the service radius which has been put forward by Japanese researchers ("as discussed by Hiroyuki [15]").

At present, the definition of public parking service radius is different in China and abroad, lacking scientific quantitative calculation methods. In China, for example, the codes provide limiting values on the service radius of public parking garage, but these values are inconsistent with each other and the service radius defined mostly refers to the early foreign datum, so it lacks scientific theoretical research. Besides, the current service scope put forward by research institutes in China and overseas is a concentric circle with a center point of parking garage, which is not in good accordance with the actual situation as it lacks consideration of city resistance and accessibility.

In view of the abovementioned facts, this study puts forward an optimization model for public parking service radius based on proposing a functional value model and a modified model of parking demand by drivers with satisfactory theory. This model can meet the requirements of both drivers and owners. In consideration of the nonuniformed distribution of city resistance, this paper also puts forward a modified model of service scope based on the theory of moment balance according to the theory of accessibility. Finally, the public parking garage of Kuixing Building in China Chongqing's CBD is taken as an example to verify practical application effects of the model by comparing the effects of the optimization model with the present situation.

\section{Influencing Factors of Public Parking Service Radius}

Influencing factors of the public parking service radius consist of two aspects: macro level and micro level. The former level includes city characteristics, land exploitation and utilization, regional traffic condition, traffic management measures, parking policy, and parking service quality, and the latter level contains parking behavior characteristics, and so forth.

City Scale. City scale has an influence on the public parking service radius in some degrees. The larger the city is, the longer the trip distance becomes, and thus drivers tend to tolerate longer walking distance.

City Resistance. Walking resistance from mountains, waters, buildings, and roads in the city will greatly influence the public parking service radius. Partial blockage caused by the above resistance will lead to a shorter service radius.

City Land Exploitation and Utilization. The different characteristics of lands determine the amount of parking demands. Parking demand is relatively concentrated in areas which have been deeply exploited. The concentration degree of demands is negatively related to the service radius.

Accessibility. Accessibility can be divided into two aspects: accessibility of the route to public parking and accessibility of walking to the destination after parking. Accessibility is to some extent positively related to the service radius.

Characteristics of Parking Behaviors. Different parking purposes lead to various walking distances after parking, for example, a commuting driver, who needs a long time for parking, with a longer walking distance after parking, can accept the larger service radius.

Service Quality. With the increasing deterioration of the traffic environment, drivers have higher requirements for parking services. The smart, humanistic, and convenient service will have stronger attraction to drivers.

Influence of Nearby Parking Lots. Drivers always want to park their cars in the location closest to their final walking destination. The utilization and convenience degree of nearby parking garages are in competition with public parking garages.

Policy Condition. Favorable policy conditions are the premise for extending service radius. Generally, congestion fee, P\&R preferential transfer, and relative preferential charging standards are adopted in China and abroad to promote attractive rates.

Of the abovementioned factors, the most significant influencing factors to public parking service radius are city resistance, land exploitation, utilization, and parking behavior characteristics. 


\section{Service Radius Model of Public Parking}

Due to different regional conditions, each public parking should have a service radius according to its own local condition. However, currently, the fixed value in codes we adopt limits its practical significance.

As for determination of public parking service radius, on the one hand, owners mostly care about service ability and comprehensive operation costs, hoping to seek an optimal relationship between these two aspects and maximize the function value of public parking. On the other hand, from the perspectives of drivers, whether to choose a public parking is largely dependent on their satisfaction degree. Therefore, this study will put forward a service radius model of public parking with consideration of both satisfaction of drivers and requirements of owners.

3.1. Basic Hypotheses. The basic hypotheses to establish the optimization model of service radius are as follows.

Basic Hypothesis 1. Location and construction cost of public parking garage have been determined.

Basic Hypothesis 2. The initial service radius $\left(R_{0}\right)$ has been determined according to codes.

Basic Hypothesis 3. The nature of the land utilization and the index of construction in the study area have been known: the legal curb parking and the matched parking spots within the initial service radius $\left(R_{0}\right)$ have been identified.

Basic Hypothesis 4. Space resistance is assumed to be uniformly distributed.

\subsection{Function Value Model of Public Parking Meeting the Needs of Owners}

\subsubsection{Definition of Model Indexes}

(i) Service Ability (S) of Public Parking Garage. Referring to related research results of site selection optimization and logistics engineering, service ability of public parking garage is defined as the comprehensive characterization of capital investment, spot scale, and comprehensive service index (measured by intelligence, humanization, and convenience) ("as discussed elsewhere [16, 17]"). The service ability of public parking garage is expressed by ("as discussed elsewhere $\left.[18,19]^{\prime \prime}\right)$

$$
S_{1}=I B^{a} P^{b} .
$$

In (1), $S_{1}$ represents service ability of public parking; $I$ stands for comprehensive services index; $B$ stands for capital investment for public parking; $P$ represents spot scale of public parking; $a$ and $b$ stand for the input-output elastic coefficients of capital and spot, respectively ("as discussed elsewhere $[18,19] ")$.

In an actual situation, service ability of public parking which has fixed parking space will be improved to some extent along with the expansion of the service scope ("as discussed by Hongzhi et al. [20]"), and owners hope to attract more parking vehicles by enhancing service ability and expanding the service scope. Service radius is positively related to service ability, and $S_{1}$ should be further amended as follows:

$$
S=S_{1} r^{\lambda}=I B^{a} P^{b} r^{\lambda} .
$$

In (2), $S$ represents the actual service ability of public parking; $r$ stands for service radius; $a$ and $b$ stand for the input-output elastic coefficients of capital and spot, respectively; the value range of $\lambda$ is $(0,3)$.

(ii) Reasonable Scale (P) Meeting the Needs of Construction Parties. The round service scope determined by the initial service radius of public parking garage $\left(R_{0}\right)$ is small; thus, firstly, we use the parking generation rate model to calculate the total demands $\left(D_{i}\right)$ within the initial service scope of public parking $(i)$. Let $k$ be the average of the parking demand generation rate per unit of land within the initial service scope of public parking $(i)$. Hence,

$$
k=\frac{D_{i}}{\pi R_{0}^{2}} .
$$

Then, parking demand $\left(P_{i}\right)$ in an area with a radius $(r)$ within the initial service radius of the public parking garage is

$$
P_{i}=k \pi r^{2} .
$$

Public parking garage mainly undertakes the overflow when the matched and curb parking spots become saturated within service scope, so the overflow is taken as the upper limit of the spot demands. Therefore,

$$
P_{\max i}=P_{i}-\sum_{i=1}^{n} p_{i}=k \pi r^{2}-\sum_{i=1}^{n} p_{i} .
$$

In (5), $P_{\max i}$ represents the upper limit of public parking garage's $(i)$ spot demands; $n$ and $p_{i}$, respectively, stand for the number of legal curb and matched parking garages and the spot amount of each public parking garage within the initial service scope of public parking garage (i).

The competitive relationship and service scope overlap between the matched and curb public parking garage within the service scope should be considered. A reasonable scale is determined on the basis of inspecting the utilization rate and turnover rate of other public parking garages within the service scope as follows:

$$
P=\frac{P_{\max i}}{\theta \varepsilon}=\frac{\left(k \pi r^{2}-\sum_{i=1}^{n} p_{i}\right)}{\theta \varepsilon} .
$$

In (6), $P$ stands for the reasonable scale after optimization of public parking; $\theta$ and $\varepsilon$ represent the average utilization rate and turnover rate within service scope of public parking garage. 


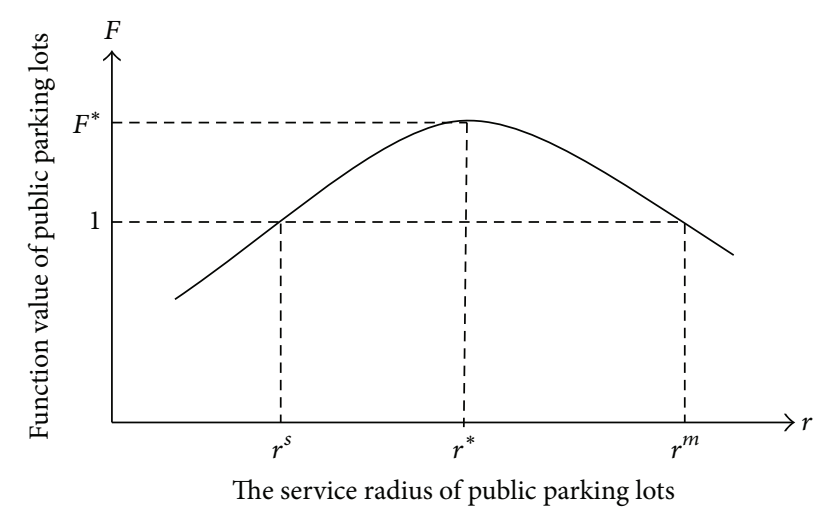

FIgURE 1: Public parking function value changes with the service radius.

(iii) Comprehensive Operation Costs (C) of Public Parking Garage. Comprehensive operation costs of public parking garage consist of the fixed costs $C_{1}$ determined by designed scale and the variable costs changing with demand. $C_{1}$ includes the operation costs of parking facilities and rent or depreciation of facilities. Variable costs include energy consumption, equipment maintenance, and labor wages. Variable costs can be calculated via direct costs (c) generated by each spot and the total amounts of spots, and then the comprehensive operation costs are

$$
C=C_{1}+c P=C_{1}+c\left[\frac{\left(k \pi r^{2}-\sum_{i=1}^{n} p_{i}\right)}{\theta \varepsilon}\right]
$$

\subsubsection{Model Establishment}

(i) Function Value (F) of Public Parking Garage. Function value of public parking garage is defined as the dynamic characteristic reflecting service ability and comprehensive operational costs of public parking garage ("as discussed by Hamacher and Nickel [21]”). Hence,

$$
F=\frac{S}{C}=\frac{I B^{a} P^{b} r^{\lambda}}{C_{1}+c\left[\left(k \pi r^{2}-\sum_{i=1}^{n} p_{i}\right) / \theta \varepsilon\right]} .
$$

From (8), if other factors remain constant, the service radius will directly affect the function value of parking garage, and the related curve is shown in Figure 1. $r^{*}$ stands for the optimal service radius only with consideration of the demands of owners, namely, to achieve efficient utilization of resources. $\left[r^{s}, r^{m}\right]$ represents the effective operational region of the public parking garage. In this region, the function value of public parking $F>1$; that is to say, the value created is higher than the operation costs, which do ensure a sustainable development.

(ii) Make the Derivation of (8) Equal to Zero. This is done as follows:

$$
\frac{d F}{d r}=\lambda\left[C_{1}-\frac{c}{\theta \varepsilon} \sum_{i=1}^{n} p_{i}\right]-\frac{k \pi r^{2} c}{\theta \varepsilon}(2-\lambda)=0
$$

The optimal service radius $\left(r^{*}\right)$ of public parking garage which meets the demands of owners after simplification is

$$
r^{*}=\sqrt{\frac{\lambda\left(C_{1} \theta \varepsilon-c \sum_{i=1}^{n} p_{i}\right)}{c k \pi(2-\lambda)}}
$$

We can deduce $C_{1}$ from (7) and then put it in (10). Through combination of these two equations, the result shows that $r^{*}$ is positively correlated with comprehensive operational costs. From owners' prospective, the higher the costs, the larger the number of parking cars that they expect, for only in this way can profits be increased, and then the service radius will be enlarged accordingly. And $r^{*}$ is negatively correlated with the parking generation rate in the region. Therefore, if the parking generation rate around the public parking garage is larger, a small service radius can meet the operation demands.

3.3. Modified Model with Consideration of Satisfaction and Demands of Drivers. Whatever the expectations of owners are, to a great extent, satisfaction degree is a vital factor for drivers to choose a public parking garage. Determining the service radius from the functional view of owners is just an ideal description of public parking operation state. Therefore, we need to modify the model according to the characteristics of drivers' demands.

There are many indexes influencing parking demand satisfaction of drivers, but the walking distance after parking is the most significant acknowledged factor which influences parking choice and parking satisfaction. Therefore, satisfaction degree of walking distance after parking is used as the evaluation index for analysis and quantization.

3.3.1. Satisfaction Model of Walking Distance after Parking. Let $t_{i}$ be the shortest walking distance which is from a public parking lot to a parking-demanded site $(i) ; L_{i}$ and $S_{i}$ are the longest walking distance in the case where drivers feel very satisfied and the tolerable walking distance in the case where drivers feel very unsatisfied, respectively. $F\left(t_{i}\right)$ is the satisfaction degree of drivers for a walking distance after parking in the public parking lot. Accordingly, $L_{i} \leq S_{i}$, so $F\left(t_{i}\right) \in[0,1]$ ("as discussed by Siskos et al. [22]").

At present, distance or time satisfaction theory is usually applied to the logistics center and the study of emergency facilities location ("as discussed elsewhere [23, 24]"). Common customer satisfaction models are linear function, concave convex function, ridge type function, decreasing semi-Cauchy type function, and exponential decay Sigmoid function ("as discussed by Yanfei [25]"). Through trail and fitting of prophase research, a ridge type or decreasing semiCauchy type time satisfaction model has been proved to be fitter for the satisfaction degree model of walking distance after parking.

(i) Ridge Walking Distance Satisfaction Model. This function has little change near thresholds $L_{i}$ and $S_{i}$, as the slope is larger 


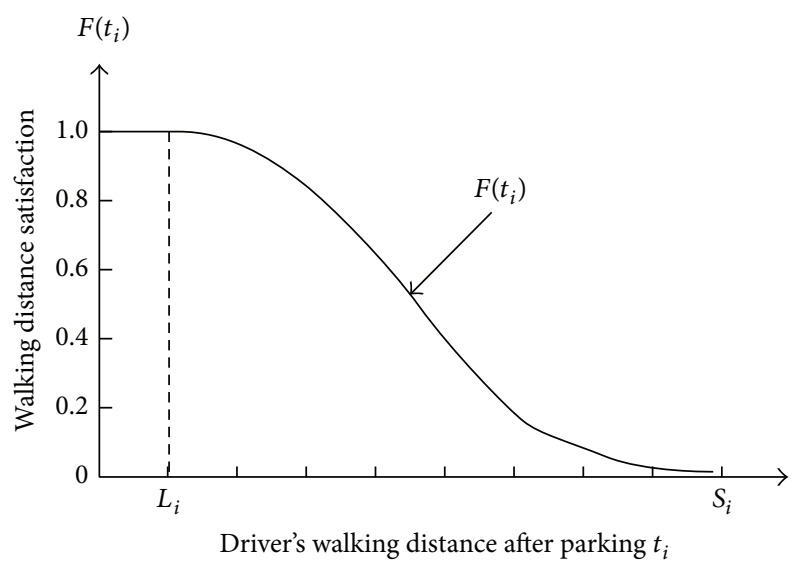

Figure 2: The curve of ridge walking distance satisfaction.

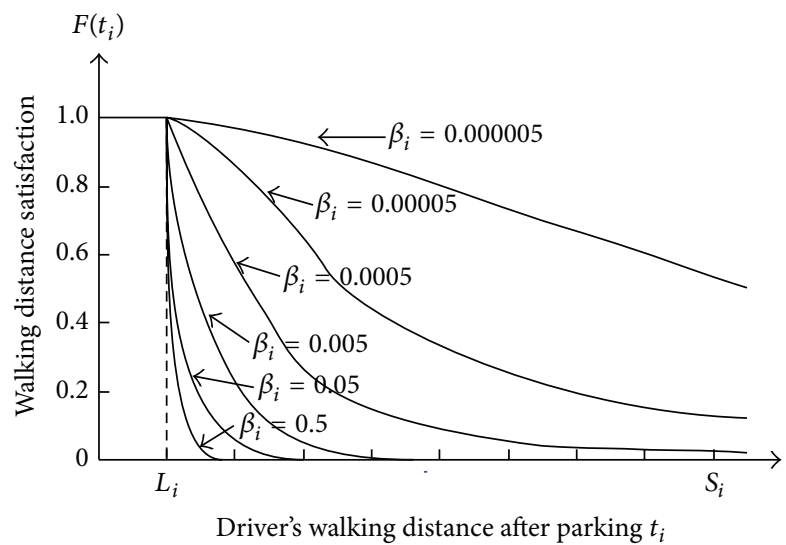

Figure 3: The curve of walking distance satisfaction.

in the middle of the curve. The functions are as follows (see Figure 2):

$$
\begin{aligned}
& F\left(t_{i}\right) \\
& = \begin{cases}1, & t_{i} \leq L_{i} \\
\frac{1}{2}+\frac{1}{2} \cos \left(\frac{\pi}{S_{i}-L_{i}}\left(t_{i}-\frac{L_{i}+S_{i}}{2}\right)+\frac{\pi}{2}\right), & L_{i}<t_{i} \leq S_{i} \\
0, & t_{i}>S_{i} .\end{cases}
\end{aligned}
$$

(ii) Decreasing Semi-Cauchy Time Satisfaction Model. This is represented as follows:

$$
F\left(t_{i}\right)= \begin{cases}1, & t_{i} \leq L_{i} \\ \frac{1}{1+\beta_{i}\left(t_{i}-L_{i}\right)^{2}}, & t_{i}>L_{i}\end{cases}
$$

where $\beta_{i}$ is a positive time sensitive coefficient. The functions are presented in Figure 3.

\subsubsection{Calculation of Thresholds $L_{i}, S_{i}$}

(i) The Longest Acceptable Walking Distance $L_{i}$ in the Case of Being Very Satisfied. American research shows that a parking lot should guarantee that $85 \sim 95 \%$ of users are within their tolerable service radius ("as discussed by Yali [26]"). After investigating parking behaviors, we count and summarize the data of walking distance after parking and then decide to use the 85th percentile walking distance after parking as the longest acceptable walking distance $L_{i 1}$.

Besides, the difference of parking purposes has great influence on the satisfactory walking distance of drivers. Thus, calculating synthetic satisfactory walking distance under different parking purposes is necessary.

Let $X=\left\{x_{1}, x_{2}, \ldots, x_{n}\right\}$ be $N$ independent parking purposes; the occupied percentage and tolerable walking distances of each parking purpose are $W=\left\{w_{1}, w_{2}, \ldots, w_{n}\right\}$ and $T=\left\{t_{1}, t_{2}, \ldots, t_{n}\right\}$, respectively, and $L_{i 2}$ is calculated by

$$
L_{i 2}=\frac{w_{1} t_{1}+w_{2} t_{2}+\cdots+w_{n} t_{n}}{w_{1}+w_{2}+\cdots+w_{n}}=\frac{\sum_{i=1}^{n} w_{i} t_{i}}{\sum_{i=1}^{n} w_{i}} .
$$

Take $L_{i}=\min \left(L_{i 1}, L_{i 2}\right)$ as the longest acceptable walking distance in the case of being very satisfied.

(ii) Tolerable Walking Distance $\left(S_{i}\right)$ in the Case of Being Very Unsatisfied. Chinese codes generally stipulate that the public parking service radius should not exceed $500 \mathrm{~m}$, and the longest service radius is within $1000 \mathrm{~m}$, so we take $S_{i 1}=$ $500 \mathrm{~m}$ here. The public parking optimal service radius $\left(r^{*}\right)$ with consideration of owners is usually much larger than the satisfactory walking distance of drivers; thus, $S_{i 2}=r^{*}$. Hence,

$$
S_{i}=\max \left(S_{i 1}, S_{i 2}\right) \text {. }
$$

3.3.3. Difference Regulatory Factors with Consideration of Drivers' Satisfaction. We can use (11) and (12) to establish a satisfaction model $F\left(t_{i}\right)$ where the driver demand-satisfied set $V=\left\{f\left(t_{1}\right), f\left(t_{2}\right), \ldots, f\left(t_{n}\right)\right\}$. The central limit theorem shows that the above large-sample investigation $(n \geq 30)$ obeys normal distribution; mean value of sample $\overline{f(t)}$ and variance $S^{2}$ are as follows:

$$
\begin{aligned}
\overline{f(t)} & =\frac{1}{n} \sum_{i=1}^{n} f\left(t_{i}\right), \\
S^{2} & =\frac{1}{n-1} \sum_{i=1}^{n}\left[f\left(t_{i}\right)-\overline{f(t)}\right]^{2} .
\end{aligned}
$$

Considering the different characteristics of parking behavior, a public parking service radius should not be a fixed value, and a dynamic interval is more practical to the actual situation. Let $f \in[0,1]$ be a difference regulatory factor which considers characteristics of drivers' satisfaction, and confidence interval which reflects differences of characteristics of drivers' satisfaction is used as the regulatory factor $f$ when the confidence range is $1-\alpha$. Hence,

$$
f \in\left[\overline{f(t)} \pm \frac{S}{\sqrt{n}} t_{\alpha / 2}(n-1)\right],
$$

where $t_{\alpha / 2}$ is the $\alpha / 2$ quantile of standard normal distribution. 
TABLE 1: City resistance relative value.

\begin{tabular}{lcccc}
\hline Land use type & Relative resistance & Influencing factors on walking & Relative resistance \\
\hline Road, square & 1 & Grade crossing & 1.1 \\
Commercial land & 1.1 & Grade separation & 1.2 \\
Residential land & 1.3 & Mountain/slope land with escalator & 1.1 \\
Public green space & 1.5 & Mountain/slope land with staircase & 1.2 \\
Land for municipal facilities & 1.8 & Mountain/slope land with elevator & 1 \\
Land for storage & 2 & Mountain, river with no crossing facilities & $+\infty$ \\
Industrial land & 5 & Height difference with no crossing facilities & $+\infty$ & $+\infty$ \\
\hline
\end{tabular}
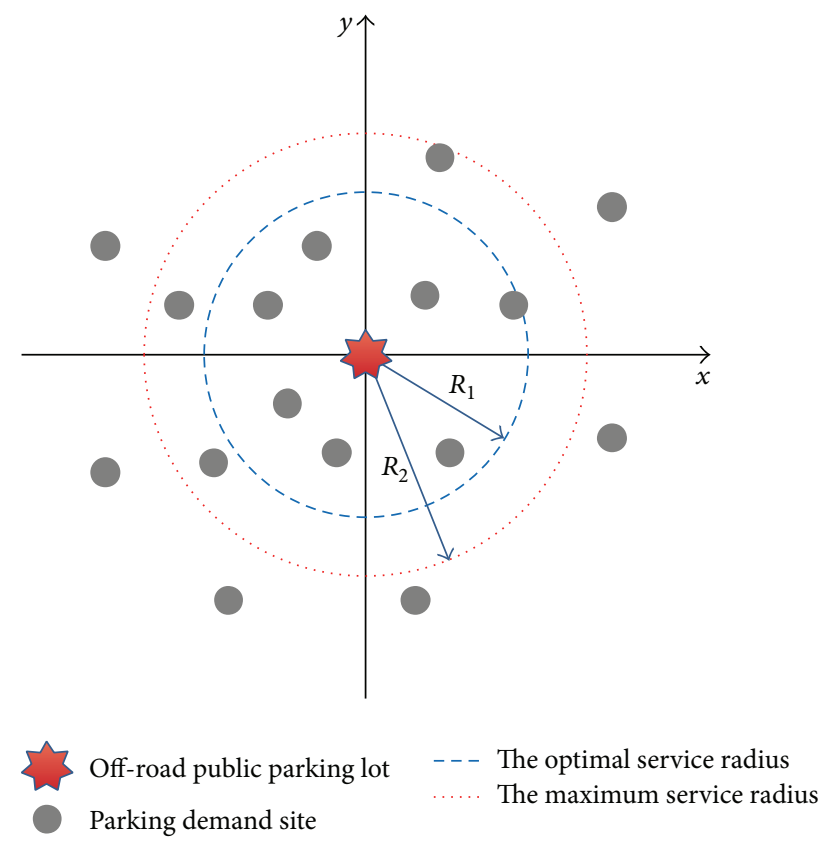

FIGURE 4: Dynamic service radius of public parking.

3.3.4. Public Parking Service Radius Optimization Model with Consideration of Demands of Drivers and Owners. By the above analysis, the public parking optimal service radius model with consideration of owners and characteristics of drivers' demands is as follows:

$$
\begin{gathered}
R=r^{*} \times f=r^{*} \times\left[\overline{f(t)} \pm \frac{S}{\sqrt{n}} t_{\alpha / 2}(n-1)\right] \Longrightarrow \\
\left\{\begin{array}{l}
R_{1}=r^{*} \times f=r^{*} \times\left[\overline{f(t)}-\frac{S}{\sqrt{n}} t_{\alpha / 2}(n-1)\right] \\
R_{2}=r^{*} \times f=r^{*} \times\left[\overline{f(t)}+\frac{S}{\sqrt{n}} t_{\alpha / 2}(n-1)\right] .
\end{array}\right.
\end{gathered}
$$

The public parking service radius calculated from (17) is a dynamic interval with consideration of demand satisfaction characteristics of owners and drivers in the case of assuming that space resistance is uniformly distributed and is used in concentric circles of which circle center is public parking (i) (Figure 4). The lower limit of the dynamic interval $R_{1}$ is the optimal service radius, and the upper limit $R_{2}$ is the maximum service radius.

\section{Optimization of Public Parking Service Scope}

The dynamic concentric circles service radius proposed by the above study is obtained by assuming the uniform distribution of space resistance. However, in reality, the accessibility of public parking is influenced by resistance caused by mountains, waters, buildings, and so forth, which results in a great change of the service scope within the public parking service radius. Especially in a mountainous city, it is more important to consider the influence of topographic height differences on accessibility. So we need to modify the service scope, making it accord with the actual situation better.

4.1. Walking Accessibility of Public Parking Garage. Without consideration of differences of space resistance distribution, based on the idea that the shortest distance between two points is a straight line, accessibility indexes of public parking garage show a concentric circle-like distribution. And if we take influence of comprehensive impedance factors into consideration such as city resistance and walking resistance, accessibility indexes will change greatly. Then, the difficulty degree to which drivers overcome resistance to go to destinations after parking is measured by the walking distance or time.

4.2. City Resistance and Walking Impedance. Walking accessibility can be extremely reduced by mountains without pedestrian passageway, water without a bridge, and topographic height differences that are hard to cross, and drivers will suffer different level resistance because they need to walk through areas with all kinds of features by different crossing facilities. Let uniform distributed city resistance be $\gamma$ and nonuniform distributed walking impedance $\gamma^{\prime}=$ $\phi \gamma$, where $\phi$ is the nonuniform distributed city resistance modification coefficient. Combined with related research datum ("as discussed by Xiaolai [27]") and parking survey datum in Chongqing, reference value of $\phi$ is as in Table 1.

4.3. Resistance Distribution Matrix and Calculation of Route Resistance. In combination with the site situation and on the basis of city land utilization, walking influence, and natural 


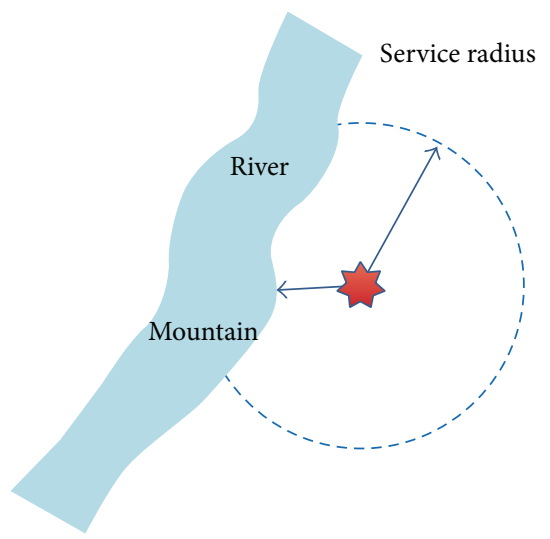

(a) Affected by river (mountain)

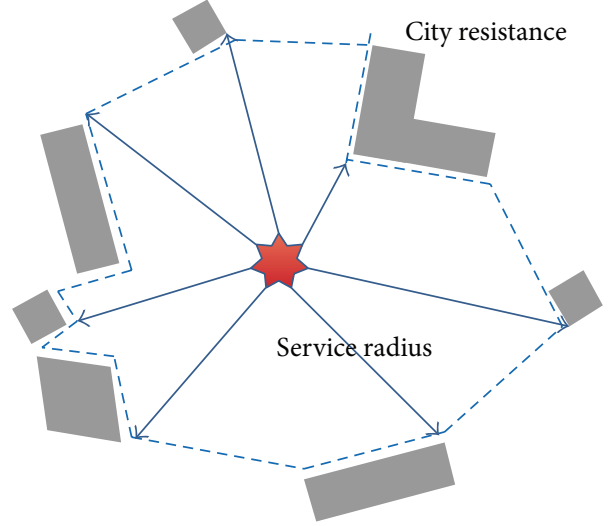

(b) Affected by building

FIGURE 5: Effect of resistance to the service radius of city parking.

barrier, the initial service scope is divided into a square grid with a certain interval. This division should center around public parking garage and then use $d_{i j}$ and $\gamma_{i j}^{\prime}$ to express walking distance and relative space impedance value of each square grid area, respectively.

Let $L=\left\{l_{1}, l_{2}, \ldots, l_{t}\right\}$ be $t$ available routes leading to a certain point of the service boundary for drivers after stopping theirs car in the public parking, and use $R_{e}\left(l_{t}\right)$ to express the accumulative resistance value of $t$ routes.

\subsection{Service Radius Modified Model Based on the Principle} of Moment Balance. Taking public parking as a centroid, divide the circular boundary with $r$ radius into $x(x \rightarrow$ $+\infty$ ) globules with the same volume $v$. The density of these globules is space resistance $\rho$. The globules and centroids are connected by connecting rods whose mass is negligible and the moment from globule to centroid is $M_{i}=F_{i} L_{i}=$ $\rho_{i} \operatorname{vgr}(i=1,2, \ldots, x)$, where $g$ is gravitational acceleration. As space resistances are uniformly distributed, all moment values $M$ are the same, so the total moment of system is $\sum M=0$, which keeps the system in a stationary state. To explain this easily, we take eight intersection points between eight direction lines in geography and service radius as an example (Figure 7).

When space resistance is distributed nonuniformly, the value $\rho$ of globule will change. With insurance of no migration of centroid and a stationary balance state of system, we need to change the length of each connecting rod (arm of force) $r_{i}^{\prime}$ to make $M_{i}=M_{i}^{\prime}$ and keep moment in balance: $\sum M=0$.

Besides, there is a special circumstance that the barrier of natural resistance cannot be crossed within service radius $\left(\rho_{i}=+\infty\right)$. To reflect an actual situation, $r_{i}^{\prime}$ represents the distance from centroid to the points of natural barrier boundary (Figure 5(a)). Then, the balance condition is $M_{i}=$ $M_{i}^{\prime}+E$, where $E$ stands for the moment produced by natural resistance.
According to the above analysis, when $\rho_{i} \neq+\infty$, we establish a modified service radius model $r_{i}^{\prime}$ :

$$
\begin{aligned}
\rho_{i} & =r \gamma \\
R_{e i}\left(l_{t}\right) & =\sum d_{i j} \gamma_{i j}=\gamma \sum d_{i j} \phi_{i j}, \quad l_{t} \in\left(l_{1}, l_{2}, \ldots, l_{t}\right) \\
\rho_{i}^{\prime} & =\min R_{e i}\left(l_{t}\right)=\min \left(\gamma \sum d_{i j} \phi_{i j}\right) \\
M_{i} & =F_{i} L_{i}=\rho_{i} v g r=\gamma v g r^{2} \\
M_{i}^{\prime} & =F_{i}^{\prime} L_{i}^{\prime}=\rho_{i}^{\prime} v g r_{i}^{\prime} \\
& \Longrightarrow r_{1}^{\prime}=\frac{\rho_{i} r}{\rho_{i}^{\prime}}=\frac{r^{2}}{\min \left(\sum d_{i j} \phi_{i j}\right)} .
\end{aligned}
$$

In (18) and (19), $\rho_{i}$ represents the density of the globule $i ; r$ is the service radius; $\gamma$ is the uniform distributed city resistance; $R_{e i}\left(l_{t}\right)$ represents the accumulative resistance value of the route $t ; d_{i j}$ and $\gamma_{i j}^{\prime}$ represent walking distance and relative space impedance value of each square grid area, respectively. $\phi$ is the nonuniform distributed city resistance modification coefficient; $M_{i}$ is the moment from globule to centroid when space resistance is uniformly distributed; $F_{i}$ and $L_{i}$ are the space resistance acting on the globule $i$ and the relevant level-arm when space resistance is uniformly distributed; and $M_{i}^{\prime}$ is the moment from globule to centroid when space resistance is uniformly distributed; $F_{i}^{\prime}$ and $L_{i}^{\prime}$ are the space resistance acting on the globule $i$ and the relevant level-arm when space resistance is uniformly distributed.

According to (19), we modify the circular distribution scope under uniform distribution of space resistance into an irregular polygon service scope with public parking garage as base point, which is more coincident with actual situation. 
TABLE 2: Satisfaction and the shortest walking distance of each point in demand.

\begin{tabular}{lcccccccc}
\hline Demand site & 1 & 2 & 3 & 4 & 5 & 6 & 7 & 8 \\
\hline$t_{i}(\mathrm{~m})$ & 184 & 204 & 106 & 148 & 431 & 490 & 442 & 394 \\
$f\left(t_{i}\right)$ & 1.000 & 0.998 & 1.000 & 1.000 & 0.357 & 0.158 & 0.316 & 0.500 \\
\hline Demand site & 9 & 10 & 11 & 12 & 13 & 14 & 15 & 16 \\
\hline$t_{i}(\mathrm{~m})$ & 249 & 311 & 324 & 345 & 487 & 496 & 381 & 367 \\
$f\left(t_{i}\right)$ & 0.954 & 0.804 & 0.761 & 0.688 & 0.167 & 0.141 & 0.551 & 0.606 \\
\hline Demand site & 17 & 18 & 19 & 20 & 21 & 22 & 23 & 24 \\
\hline$t_{i}(\mathrm{~m})$ & 208 & 248 & 233 & 312 & 245 & 338 & 427 & 499 \\
$f\left(t_{i}\right)$ & 0.997 & 0.956 & 0.977 & 0.800 & 0.960 & 0.713 & 0.372 & 0.133 \\
\hline
\end{tabular}

\section{Case of Application}

5.1. Case Background. We carry out our experiment in Kuixing Parking Building, an 8-storey self-propelled tridimensional public parking building (925 spots) in Jiefangbei CBD, Chongqing, China, whose use characteristics are complex, and the parking demands here are large. However, in practical operation, although demands for parking spots exceed supplies in CBD, the spot utilization of Kuixing Building fails to reach expectation, and high vacancy rate leads to waste of resource. So, we use the models and methods proposed by this paper to redetermine the service radius of this public parking and optimize parking spot scale and then compare them to the present situation.

5.2. Application of Service Radius Model. According to the codes, service radius of this public parking garage is $R_{0}=$ $500 \mathrm{~m}$; the total demand within initial service scope is $D_{i}=$ 18055 spots; then, we get $k=2.3$ spots $/ 100 \mathrm{~m}^{2}$. Fixed cost is $C_{1}=50$ million yuan and direct cost of unit spot is $c=0.0026$ million yuan/spot; there are $n=24$ various public parking spots within the initial service scope, so the total amount of spots is 13991 . The regulatory factor is $\lambda=0.7$; spot utilization is $\theta=84 \%$; turnover rate is $\varepsilon=3.8$. According to (10), we can obtain the optimal service radius $r^{*}=594 \mathrm{~m}$ which meets the demands of owners.

By conducting an investigation about parking behavior, customers' satisfaction degree on walking distance within initial service scope can be fitted by a mountain type model, where $L_{i}=194 \mathrm{~m}$ and $S_{i}=594 \mathrm{~m}$. The shortest walking distance $t_{i}$ from 24 parking-demanded places within the initial service scope to the public parking and values of satisfaction function obtained are as in Table 2.

According to (15), $\overline{f(t)}=0.663$ and $S^{2}=0.103$ can be obtained. Then, let the confidence level be $95 \%$, and regulatory factor $f \in(0.619,0.707)$ is carried out. Finally, bring parameter $\overline{f(t)}$ into (17) and make out the service radius of this public parking garage: $R_{1}=368 \mathrm{~m}$ and $R_{2}=420 \mathrm{~m}$. The dynamic interval is $R \in(368 \mathrm{~m}, 420 \mathrm{~m})$.

5.3. Application of Modified Service Scope Model. In combination with site situation of this public parking, 8 direction lines in geography are taken as the datum line to construct 16 points with modified radius (Figure 9). Suppose the uniform

\begin{tabular}{|c|c|c|c|c|c|c|c|c|c|}
\hline 1 & 2 & 3 & 4 & . & & $m-$ & $m-1$ & $m$ & \\
\hline$Q$ & 1.5 & $\langle 4 A$ & -3 & $y_{i j}^{\prime}$ & 4 & 5 & 2 & 1 & 1 \\
\hline 2 & $2 B$ & 2.2 & 1 & . & 1 & 1.5 & 2 & 4 & 2 \\
\hline 3.2 & 4 & 1.3 & 2 &. & 3 & 2.3 & 1 & 3.5 & 3 \\
\hline 1 & 1 & 1 & 3.5 & $\cdots$ & 1 & 3 & 2.4 & 2 & 4 \\
\hline$r_{i j}$ & $\ldots$ & 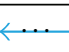 & $\ldots$ & 1 & $\ldots$ & $\cdots$ & $\ldots$ & $\ldots$ & \\
\hline 1.5 & 1.5 & 1.5 & 2 & $\ldots$ & 1.5 & 1 & 2 & 3 & \\
\hline 4 & 4 & 2 & 3 & $\ldots$ & 1.6 & 2 & 1.3 & 4.2 & \\
\hline 2 & 2.5 & 1.3 & 1 & $\ldots$ & 2.6 & 4 & 3 & 5 & $n-1$ \\
\hline 4 & 3 & 1 & 1 & $\ldots$ & 3.8 & 1.3 & 5 & 2 & $n$ \\
\hline
\end{tabular}

Public parking lot $\mathrm{ABC}$ Different routines

FIgURE 6: Resistance spatial distribution matrix.
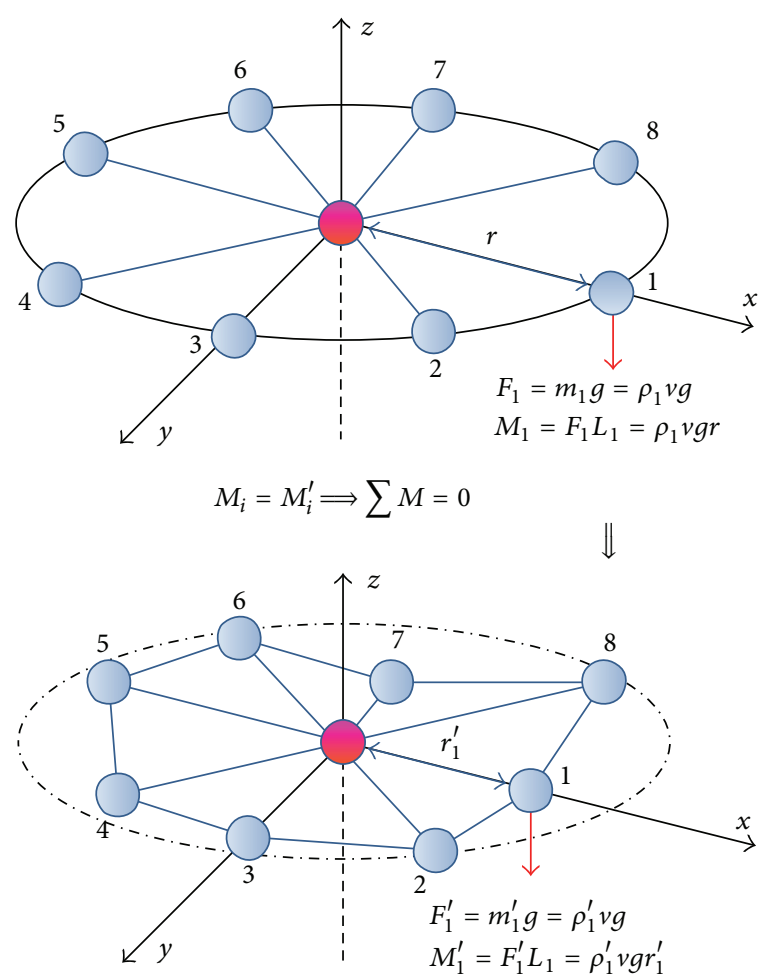

FIGURE 7: Radius optimization based on the principle of moment balance.

distributed city resistance is 1 , and then calculate the relative value of nonuniform distributed city resistance by Table 1 . Next, establish the distribution matrix of resistance (Figure 6) and calculate the accumulative resistance value of each route to get $\rho_{i}^{\prime}$. The results modified according to Section 4.4 are shown in Table 3 and Figure 8.

5.4. Result Analysis. Before service scope optimization, the utilization of 925 parking spots in this public parking during workdays and holidays is shown in Figure 9. 


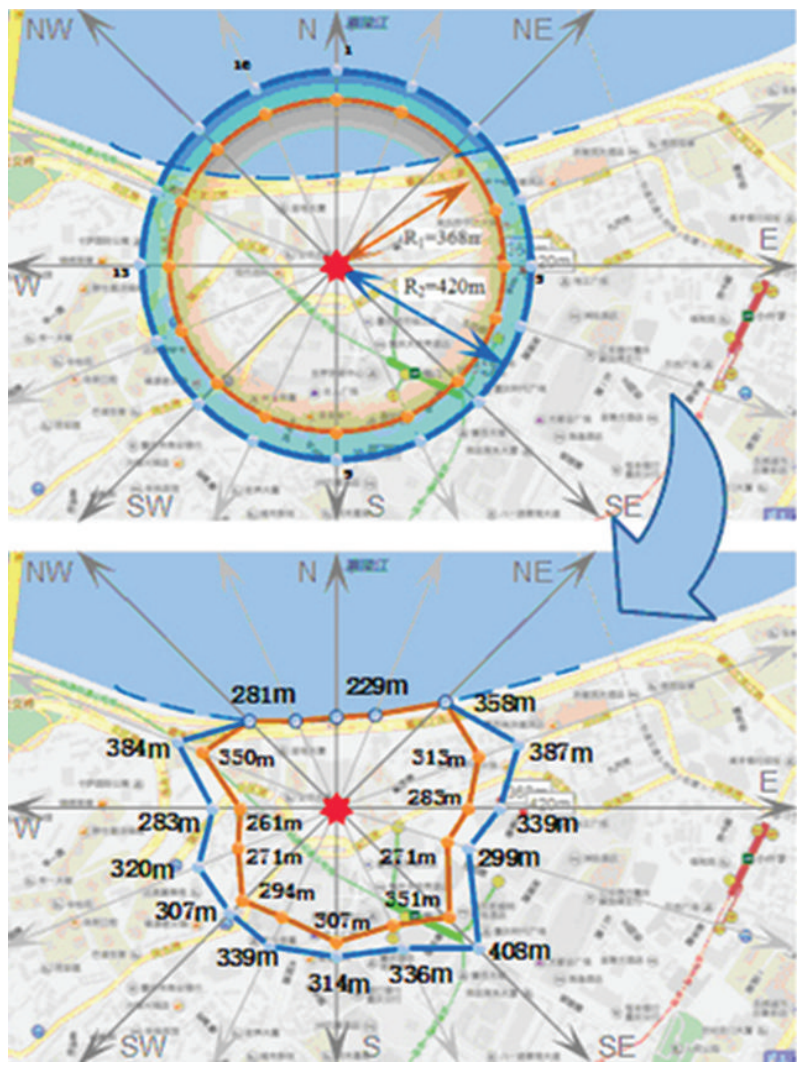

FIGURE 8: Diagram of modified service scope.

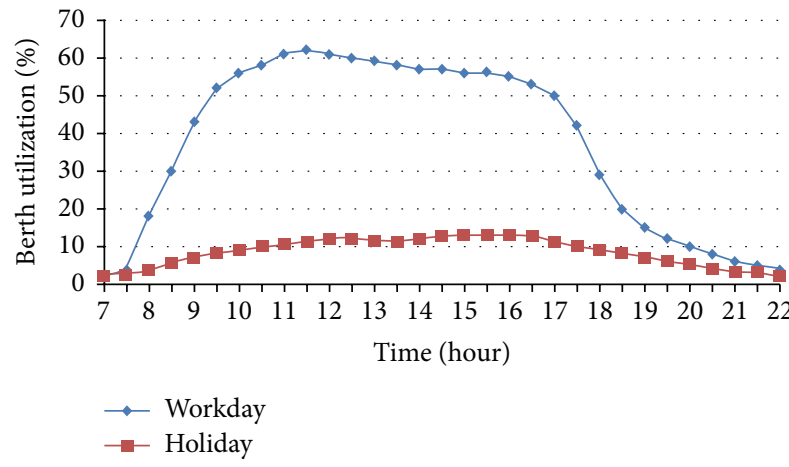

FIgure 9: Utilization rate of Kuixing Public Parking Building.

Our analysis from the view of owners, with consideration of construction and operation, is as follows. The amount of parking spots is redetermined on the basis of the modified service scope. According to the study in Section 3.2, there are 722 spots after optimization. The maximum utilization rate of workday parking is improved from $62 \%$ to $74.9 \%$ and of holidays from $12.8 \%$ to $16.4 \%$. It shows that the utilization of parking lot is improved significantly. So the main reason for the low utilization of this public parking is the large quantity of parking spots supply caused by the overdesigned service radius. By optimizing the service scope, the reoptimized spot supply is much more in accord with the present utilization. Therefore, we cannot blindly pursue a large service radius and more parking spots when constructing public parking.
TABLE 3: Modified calculation table for service scope.

\begin{tabular}{lcccccccc}
\hline Datum point & 1 & 2 & 3 & 4 & 5 & 6 & 7 & 8 \\
\hline$\rho_{i 1}^{\prime}$ & - & - & - & 433 & 478 & 499 & 386 & 481 \\
$R_{1}^{\prime}(\mathrm{m})$ & 229 & 266 & 358 & 313 & 283 & 271 & 351 & 282 \\
$\rho_{i 2}^{\prime}$ & - & - & - & 456 & 521 & 590 & 432 & 525 \\
$R_{2}^{\prime}(\mathrm{m})$ & 229 & 266 & 358 & 387 & 339 & 299 & 408 & 336 \\
\hline Datum point & 9 & 10 & 11 & 12 & 13 & 14 & 15 & 16 \\
\hline$\rho_{i 1}^{\prime}$ & 441 & 485 & 461 & 500 & 519 & 387 & - & - \\
$R_{1}^{\prime}(\mathrm{m})$ & 307 & 279 & 294 & 271 & 261 & 350 & 281 & 253 \\
$\rho_{i 2}^{\prime}$ & 562 & 521 & 575 & 552 & 624 & 459 & - & - \\
$R_{2}^{\prime}(\mathrm{m})$ & 314 & 339 & 307 & 320 & 283 & 384 & 281 & 253 \\
\hline
\end{tabular}

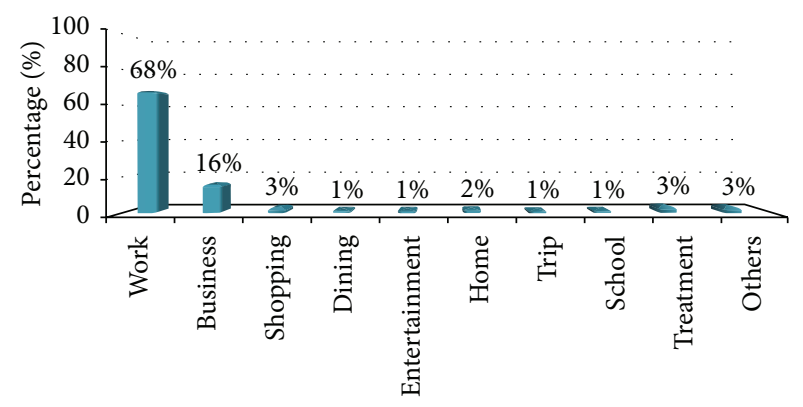

Parking purposes

Figure 10: Parking purposes of drivers.

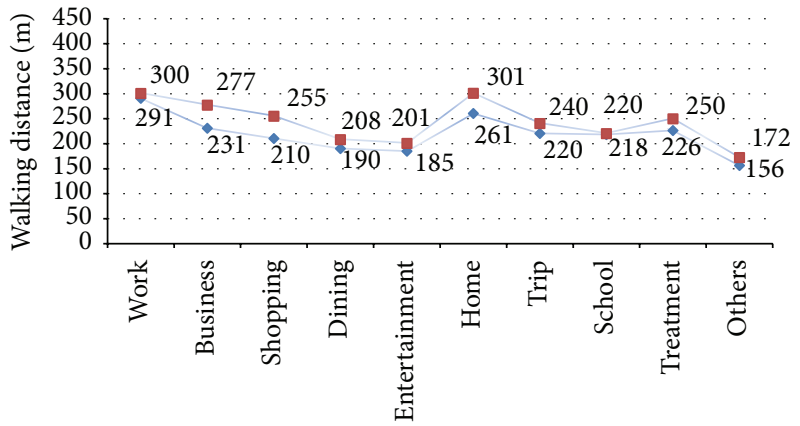

$$
\begin{aligned}
& \text { Parking purposes }
\end{aligned}
$$

FIGURE 11: Walking distance and acceptable distance of drivers with different parking purposes.

A moderate scale and dispersed layout will effectively relieve hard-parking.

Our analysis from the view of drivers, with consideration of satisfaction in walking distance after parking, is as follows. According to Table 3 and Figure 8, the optimal service radius is $R_{1}=229 \mathrm{~m}$ and the maximum service radius is $R_{2}=408 \mathrm{~m}$. We have made RP (Revealed Preference Survey) and SP (Stated Preference Survey) investigation of drivers in Kuixing Parking Building. And Figure 10 shows the results of parking purposes; Figure 11 shows the results of walking distance and acceptable distance after parking from drivers with different parking purposes. 
Figures 10 and 11 show that, as for this parking building, those who park for working, business, and shopping account for $87 \%$ of the total amount of drivers and they are the main service object. For 95\% of drivers except for parking users for the purpose of dining and entertainment and a few drivers who have other purposes, the walking distances and acceptable distances after parking are within both the optimal service radius and the maximum service radius. The results meet the requirement mentioned above that parking lot should guarantee that $85 \sim 95 \%$ of users are within their tolerable service radius. Therefore, we can conclude that the models and methods proposed by this paper are in good accordance with the results obtained from the investigation of the driver's parking behavior. And the present service radius of this parking building is overlarge, exceeding the maximum acceptable service radius of drivers and failing to meet the satisfaction in walking distance of drivers, which is one of the reasons why the utilization of the parking building cannot reach the expectation.

\section{Concluding Remarks and Future Research}

A scientifically rational service radius of public parking has a great significance for reasonably determining parking spot scale and improving utilization of public parking. The innovative highlights of this research are as follows:

(1) Based on the theory of value engineering and satisfaction, the optimization model for public parking garage service radius is established, which satisfies the requirements of both drivers and owners.

(2) According to the accessibility theory and principle of moment balance, we modify the circular service scope to an irregular polygon service scope with consideration of city resistance and walking impedance; thus, it is more coincident with the actual situation.

(3) This study proposes new thoughts and methods to determine service radius and scope of off-street public parking garages, remedying the defects of determining service radius according to experience.

(4) The application of research results improves the whole operational efficiency of public parking on the basis of considering the demand satisfaction of both owners and drivers, which promotes the sustainable development of city and alleviates the public parking pressure.

Furthermore, due to the related replacement between parking fee and walking distance, there is the possibility of adjusting the public parking service scope by means of policies. Therefore, how to introduce policy factors into this model and method will be the future direction of this study.

\section{Competing Interests}

All the authors of this paper declare that they have no financial or personal relationships with other people or organizations that can inappropriately influence their work, and there is no professional or any other personal interest of any nature or kind in any product, service, and/or company that could be construed as influencing the position presented in the paper.

\section{Acknowledgments}

This research was financially supported by the National Natural Science Foundation of China (E080701) and the Municipal Technology Plan of Chongqing (2013-11).

\section{References}

[1] M. Jelokhani-Niaraki and J. Malczewski, "A group multicriteria spatial decision support system for parking site selection problem: a case study," Land Use Policy, vol. 42, pp. 492-508, 2015.

[2] N. Levy and I. Benenson, "GIS-based method for assessing city parking patterns," Journal of Transport Geography, vol. 46, pp. 220-231, 2015.

[3] W. Clayton, E. Ben-Elia, G. Parkhurst, and M. Ricci, "Where to park? A behavioural comparison of bus Park and Ride and city centre car park usage in Bath, UK," Journal of Transport Geography, vol. 36, pp. 124-133, 2014.

[4] E. Chaniotakis and A. J. Pel, "Drivers' parking location choice under uncertain parking availability and search times: a stated preference experiment," Transportation Research Part A: Policy and Practice, vol. 82, pp. 228-239, 2015.

[5] P. van der Waerden, H. Timmermans, and A. N. R. da Silva, "The influence of personal and trip characteristics on habitual parking behavior," Case Studies on Transport Policy, vol. 3, no. 1, pp. 33-36, 2015.

[6] A. Ibeas, L. Dell'Olio, M. Bordagaray, and J. D. D. Ortúzar, "Modelling parking choices considering user heterogeneity," Transportation Research Part A: Policy and Practice, vol. 70, pp. 41-49, 2014.

[7] J. Simićević, S. Vukanović, and N. Milosavljević, "The effect of parking charges and time limit to car usage and parking behaviour," Transport Policy, vol. 30, pp. 125-131, 2013.

[8] A. Gragera and D. Albalate, "The impact of curbside parking regulation on garage demand," Transport Policy, vol. 47, pp. 160$168,2016$.

[9] E. Inci and R. Lindsey, "Garage and curbside parking competition with search congestion," Regional Science and Urban Economics, vol. 54, pp. 49-59, 2015.

[10] G. Pierce, H. Willson, and D. Shoup, "Optimizing the use of public garages: pricing parking by demand," Transport Policy, vol. 44, pp. 89-95, 2015.

[11] M. C. Childs, Parking Space, The McGraw-Hall Compaines, New York, NY, USA, 1999.

[12] M. B. W. Kobus, E. Gutiérrez-i-Puigarnau, P. Rietveld, and J. N. Van Ommeren, "The on-street parking premium and car drivers' choice between street and garage parking," Regional Science and Urban Economics, vol. 43, no. 2, pp. 395-403, 2013.

[13] Y. Yang, H. Hao, and L. Yun-Xia, "Parking choice behaviorbased optimization model of service radius of road outside public parking," in Proceedings of the 19th Cross Straits Symposium on Urban Traffic, pp. 428-434, Guiyang, China, 2011.

[14] USA City Land Use Institute, Z. Sheng, S. Ping, and W. LiJun, Foreign Design of Parking, Intellectual Property Publishing Home, Beijing, China, 4th edition, 2003.

[15] Y. G. Hiroyuki, Business and Investment of Multistory Parking, Urban Co., Tokyo, Japan, 1991. 
[16] A. R. Mahmud and V. Indriasari, "Facility location models development to maximize total service area," Theoretical and Empirical Researches in Urban Management, vol. 4, no. 1, pp. 87100, 2009.

[17] A. Tamir, "The $k$-centrum multi-facility location problem," Discrete Applied Mathematics, vol. 109, no. 3, pp. 293-307, 2001.

[18] W. Fanian, Research on Service Radius of Logistics Node Based on the Satisfactory Degree Theory, Xidian University, 2010.

[19] Z. Drezner and C. Scott, "Locating a service facility with some unserviced demand," IMA Journal of Management Mathematics, vol. 17, no. 4, pp. 359-371, 2006.

[20] G. Hongzhi, Z. Yuhong, C. Hongbo, and L. Xiaoming, "A methord on forecasting the scale of a logistics center," China Civil Engineering Journal, vol. 38, no. 5, pp. 96-99, 2005.

[21] H. W. Hamacher and S. Nickel, "Classification of location models," Location Science, vol. 6, no. 1-4, pp. 229-242, 1998.

[22] Y. Siskos, E. Grigoroudis, C. Zopounidis, and O. Saurais, "Measuring customer satisfaction using a collective preference disaggregation model," Journal of Global Optimization, vol. 12, no. 2, pp. 175-195, 1998.

[23] M. A. Yun-Feng, M. Zhang, and J. Yang, "Definition and application of time satisfaction function in logistics facility location," Logistics Technology, vol. 9, pp. 26-29, 2005.

[24] F. Lei and H. Jianmin, "Optimal location model and algorithm of urban emergency systems," Journal of Management Sciences in China, vol. 2, pp. 12-15, 2005.

[25] S. Yanfei, Research on Time-Satisfaction Logistic Facility Location and Distribution System, Zhejiang University of Technology, Hangzhou, China, 2007.

[26] L. Yali, Research on Supply-Demand of Parking Planning in Urban Central District, Southwest Jiaotong University, Chengdu, China, 2008.

[27] Z. Xiaolai, GIS-Based Researches on Service Radius of Urban Public Park, Huazhong Agricultural University, Wu Han, China, 2007. 


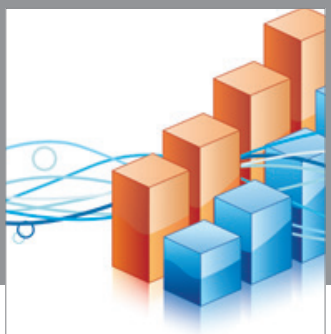

Advances in

Operations Research

vatem alat4

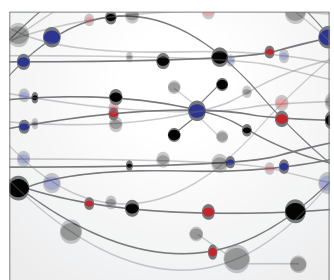

\section{The Scientific} World Journal
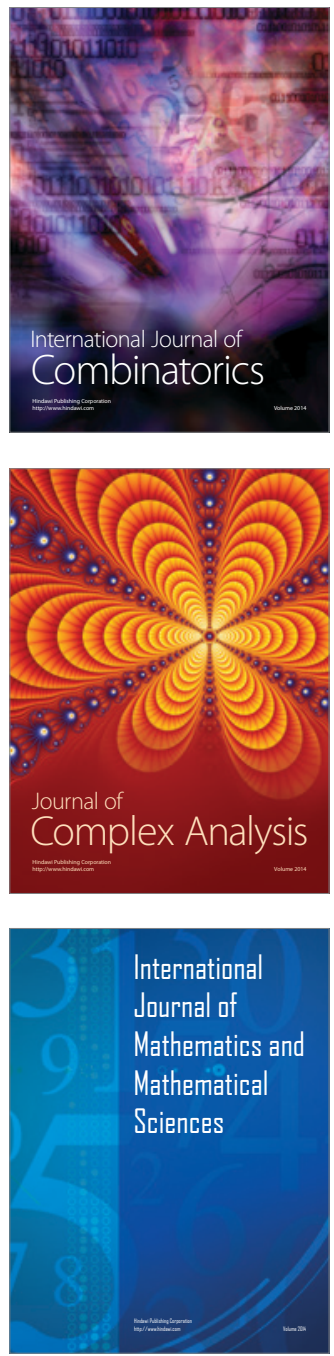
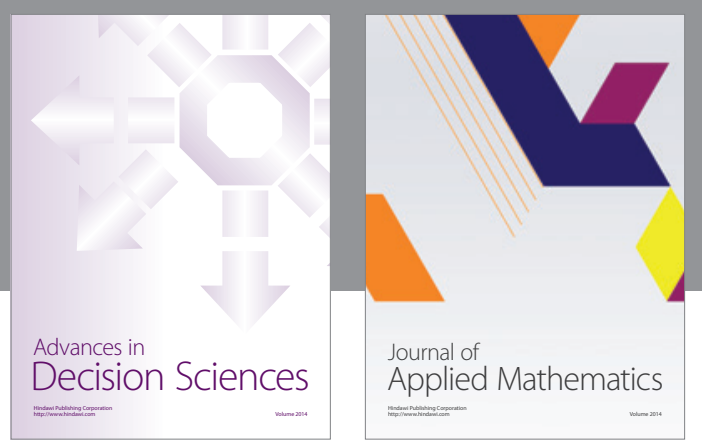

Algebra

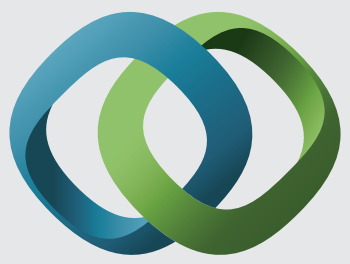

\section{Hindawi}

Submit your manuscripts at

http://www.hindawi.com
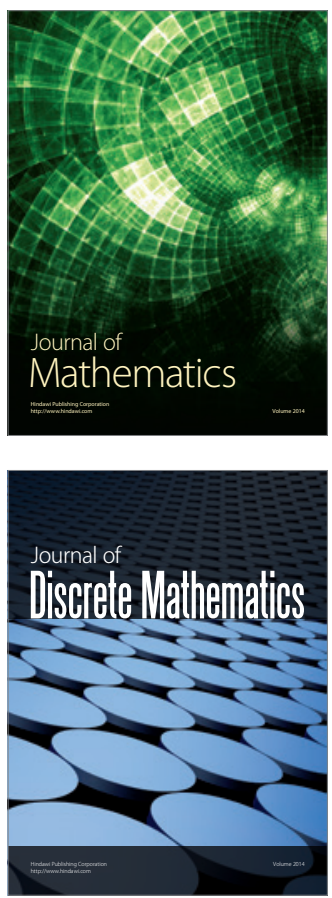

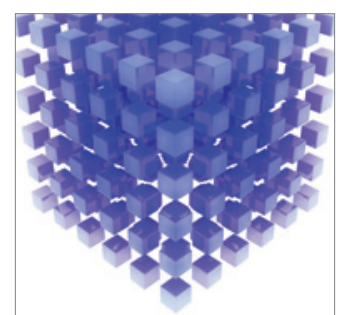

Mathematical Problems in Engineering
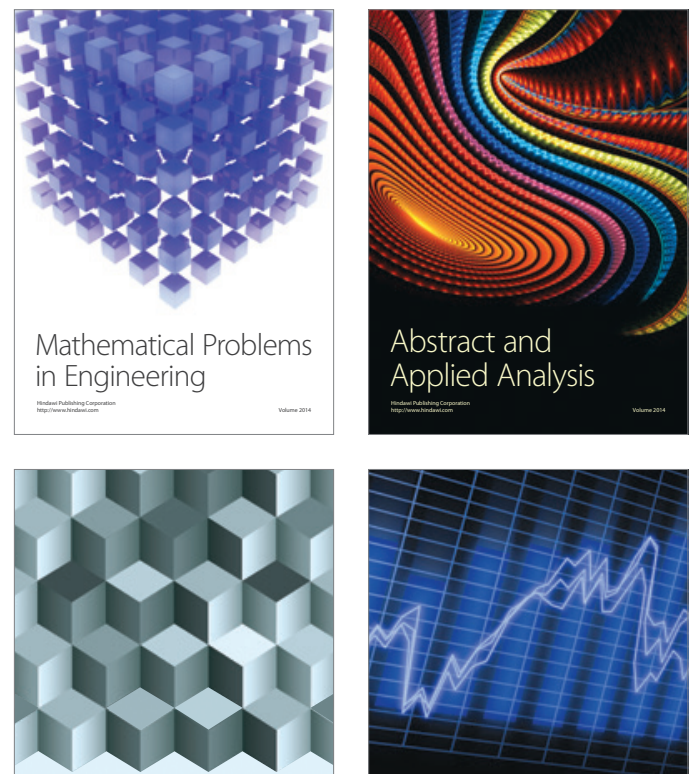

Journal of

Function Spaces

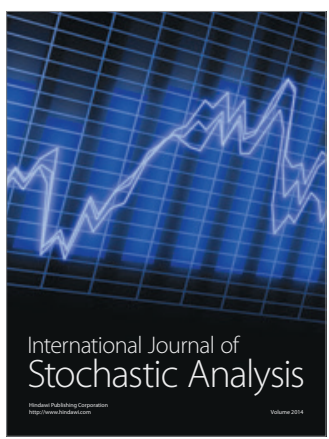

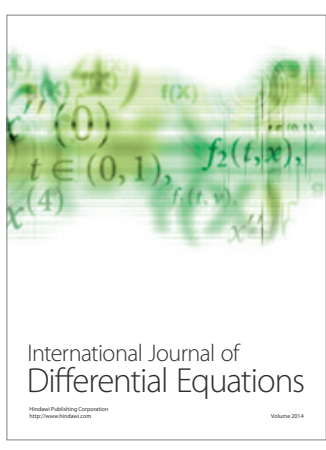
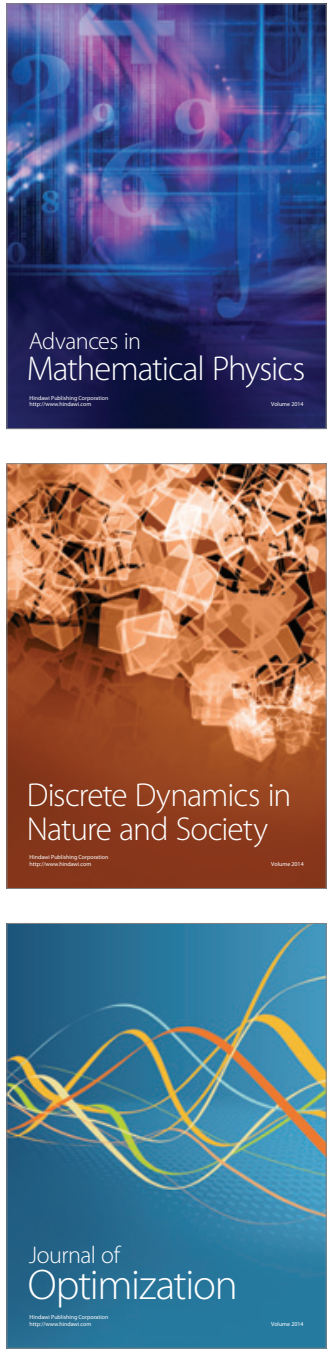